\title{
Sustainable Home Energy Management of Movement Control Order due to Pandemic Covid-19 by Using 5Core Procedure Method
}

\author{
Mohamad Fani Sulaima ${ }^{1}$, Nawa Izzati Ahmad Zaki², Musthafah Mohd Tahir ${ }^{3}$, \\ Muhd Muhtazam Noor Din ${ }^{4}$ and Zul Hasrizal Bohari ${ }^{5}$ \\ ${ }^{1}$ Senior Lecturer, Faculty of Electrical Engineering, Universiti Teknikal Malaysia Melaka, Malaysia. \\ ${ }^{2}$ Senior Teacher, Sekolah Menengah Kebangsaan Ayer Keroh, Melaka, Malaysia. \\ ${ }^{3}$ Asscociate Professor, Faculty of Mechanical Engineering, Universiti Teknikal Malaysia Melaka, Malaysia. \\ ${ }^{4}$ Head, Sustainable Energy Department, Malaysia Green Technology and Climate Change Centre, Malaysia. \\ ${ }^{5}$ Senior Lecturer, Faculty of Electrical and Electronic Engineering Technology, Universiti Teknikal Malaysia Melaka, Malaysia. \\ ${ }^{I}$ ORCID: 0000-0003-1600-9539
}

\begin{abstract}
During the movement control order (MCO), most of the citizen stay at home. Thus, it increased electricity consumption tremendously. The uncontrolled consumption of electricity happened when a lack of awareness among residents to practice home energy efficiency. Due to that reason, this study presents a real case of the MCO electricity energy waste during the early MCO stage. In contrast, sustainable home energy management with 5Core procedures was introduced to overcome the issue. The method was applied to manage people's activities inside the house, where the best arrangement of the energy efficiency approach has been used accordingly. Through the proposed process, energy consumption has significantly reduced while avoiding the spike of the electricity bill during the post-MCO of Pandemic COVID-19. The sustainability of the post MCO for the energy consumption among residential could contribute to the low $\mathrm{CO} 2$ emission while securing the factor of the costeffectiveness for the electricity bill. It is hoped that the proposed method will be the guideline for the consumers to manage the consumption of the electricity, where the combination of the human factor will be the advantages.
\end{abstract}

Keywords: Movement Control Order, Sustainable, Home Energy Management, Covid-19

\section{INTRODUCTION}

Pandemic Covid-19 has spread globally, while the movement control order (MCO) has been introduced to cessation the virus chain. In Malaysia, the MCO method has been applied to most of the outdoor social activities that were prohibited. The campaign during MCO, such as“ stay at home’ has brought much impact to residential energy consumption. The surge of energy consumption among residential happened when less awareness of the social and technology synchronization of energy efficiency practice [1]. Under the energy efficiency (EE) program, so-called energy management has been introduced in the international organization for standard (ISO) procedure such as ISO 50001 is purposely to encourage any organization in best practicing EE up to standard [2]. The ISO 50001 was inspired by the appropriate arrangement of the organization management to ensure efficient energy consumption while supporting the synchronization of good practice worldwide. In ASEAN, there was introduced of ASEAN Energy Management Scheme (AEMAS) to help sustainable energy management schemes improve the procedure of ISO 5000. The AEMAS consists of the assessment for the targeted energy consumption saving with the star rating to the recognize organization. Meanwhile, certified the person who involve in managing the energy management system [3].

In Malaysia, the AEMAS was implemented in individual commercial buildings, mostly in government hospitals, while the certified energy manager under the scheme was increasing every year [4]. However, most of the energy management procedures include ISO 50001 was focusing on the organization rather than household consumers. The study of the home energy management under the EE program was less presented in the past literature, while the majority of the references focusing on the demand response program that integrated the load scheduling to the price based program such as TOU tariff as explained in [5], [6]. The providers introduced TOU, while consumers join the plan to reduce the cost of the electricity bill. In this case, energy consumption reduction was not a priority, while consumers can shift their activities to the low-cost price tariff zones [7]. In the meantime, the generation gained benefits through the mitigation of the peak demand as well as reduce generation stress [8].

Unlike sustainable home energy management (SHEM), the main goal of the practice is to reduce energy consumption. At the same time, most of the activities could reduce $\mathrm{CO} 2$ emission and save the environment congruently [9]. Before the SHEM implementation, the energy audit work was proposed [10]. The method of the audit procedure was adopted from the building assessment with the small scale of the scope. As the output recommendation from the audit was less synchronize, the arrangement of the sufficient SHEM would not be made accordingly. At the same time, there was less SHEM procedure (EE program context) in past studies. Hence, the improved 
energy management procedure is required so that the efficiency program would be sustained. The conceptual framework of the energy policy and the government commitment towards implementation of better SHEM in Malaysia has been explained in [11]. For example, the appliances of energy efficiency labeling project with stars rating. The government encourages the household to buy five-star appliances so that the home energy consumption could be reduced tremendously. However, the method was less effective when the family uses the devices without the excellent practice of SHEM procedure.

Meanwhile, the impact of the energy consumption surge would have happened during critical conditions such as MCO of pandemic COVID-19. To the best of the knowledge, there was a lack of the effectiveness of SHEM, such as during MCO of the pandemic. In this study, a novel of the SHEM by using the 5Core Procedure method has introduced. Meanwhile, the effectiveness of the technique has been tested in real MCO conditions. The ability of the proposed method is applicable in all situations, while most of the practical results could be achieved in a short period. In explaining the details of the proposed method and the test impact, the arrangement paper is presented as follows. Section 2 presents the proposed 5Core Procedure of SHEM, while Section 3 discusses the case studies derivation. Meanwhile, Section 4 demonstrates the analysis and discussion of the proposed method were implemented. Lastly, Section 5 concludes the overall research.

\section{SHEM WITH 5CORE PROCEDURE}

SHEM with 5Core procedure has been formatted based on real experiences of the Pandemic MCO in Malaysia. The step of the procedure in supporting of EE program has been explained as followed.

Core-Awareness: The first step of the awareness that there is forecasted that electricity bill surge during MCO will have happened tremendously. Apart from that, the awareness procedure should stress the importance of environmental sustainability when electricity is not effectively consumed. The knowledge about the relationship between energy consumption and the impact of global warming, increase of the global temperature, natural disaster, and the increase of the sea level must be encouraged appropriately. When all these have been addressed, the household understands 'why' the next step should be taken immediately.

Core-Preparation: Prepare sharing space for many activities for the household. Prepare to open the window so that natural lighting could support the space area while wind flow could quickly help to reduce the in-house temperature.

Core-Systematic: The systematic part refers to how efficient the appliances have been used to avoid waste of energy. The systematic of the switch ON and OFF of the appliances and the setting up to meet the optimum requirement of the household condition. An example of that is the increased air-conditioning temperature for the long run condition (24 Celsius is the best).
Timer setting should be applied for the night mode condition. Another example was charging the appliance or gadget such as phone, laptop, tablet during regular hours so that the full charge capacity would be monitored. Thus, the overcharging condition would be avoided and reduce the possibility of the energy wasted happen.

Core-Supervise: Supervision is vital for energy efficiency or energy management to be successful. For the best practice, it has been suggested that the household identify a person that can monitor all the activities. This supervisor will make sure all the appliances are switch-off when not use, such as doing housekeeping. For those households that have been installed by Smart Meter, the supervisor would refer to the load profile of the electricity consumption so that a simple analysis of the consumption status would be defined.

Core-Repeating: To sustain the efficiency of the SHEM method, the repeating part of the procedure 2.1 until 2.4 must be a regular practice. If there is an unsuitable condition for the household activities, the setting condition shall be applied when other solutions would become the best solution specific to the household activities during MCO. Meanwhile, the appropriate electricity bill increase, the flow of the SHEM should back to the awareness step. Hence, Fig. 1 summarizes the flow of the SHEM method accordingly.

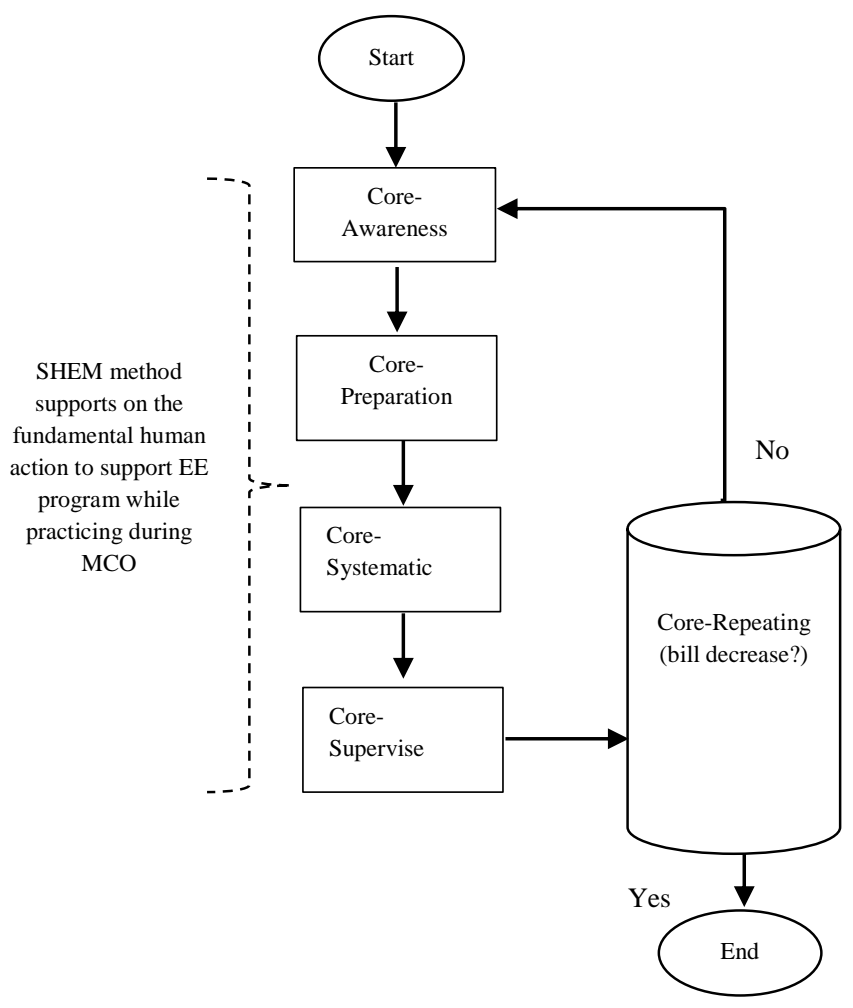

Fig. 1. Flow of the proposed SHEM method for the residential electricity consumers 


\section{CASE STUDY}

The case study has been arranged as follows:

Case 1: The case of the baseline of the MCO without Awareness and SHEM method

Case 2: The case with awareness without proper SHEM method

\section{Case 3: The case with SHEM method}

The case has referred to the household with the capacity of appliance installation, as in Table 1 accordingly. The incoming was a single line connection with a $240 \mathrm{~V}$ supply. The average of the maximum demand was $4 \mathrm{~kW}$. The average baseline energy consumption was $42.8 \mathrm{kWh}$, and the peak period was divided into two allocations: 03:00 PM to 04:00 PM and 09:00 PM to 12:00 AM, respectively. The built-up area of the house is 1,600sqft. Thus, Fig. 2 shows the baseline energy consumption profile for the home type in Melaka, Malaysia.

Table 1. List and capacity of the electrical appliances in the house that has been operated during MCO

\begin{tabular}{|c|c|c|c|}
\hline Appliances & Units & $\begin{array}{l}\text { Power rated } \\
(\mathrm{kW}) / \text { unit }\end{array}$ & $\begin{array}{l}\text { Consumption } \\
\text { (hours) }\end{array}$ \\
\hline Ceiling Fan & 4 & 0.012 & 20 \\
\hline Wall Fan & 3 & 0.010 & 20 \\
\hline Downlight (LED) & 7 & 0.012 & 10 \\
\hline $\begin{array}{l}\text { T5 } \\
\text { (LED) }\end{array}$ & 4 & 0.018 & 8 \\
\hline $\begin{array}{ll}\text { T8 } & \text { Lighting } \\
\text { (LED) } & \end{array}$ & 1 & 0.028 & 5 \\
\hline Chandelier Light & 3 & 0.036 & 5 \\
\hline Freezer & 1 & 0.920 & 24 \\
\hline $\begin{array}{l}\text { Washing } \\
\text { Machine }\end{array}$ & 1 & 0.800 & 4 \\
\hline Water Heater & 1 & 3.330 & 1 \\
\hline Microwave & 1 & 1.200 & 1.5 \\
\hline Water Dispenser & 1 & 0.950 & 24 \\
\hline Television & 1 & 0.150 & 10 \\
\hline $\begin{array}{l}\text { Internet } \\
\text { router }\end{array}$ & 1 & 0.001 & 24 \\
\hline Laptop & 1 & 0.250 & 8 \\
\hline Desktop & 1 & 0.350 & 10 \\
\hline Phone (Charging) & 1 & 0.001 & 4 \\
\hline Air Filter & 1 & 0.250 & 8 \\
\hline $\begin{array}{l}\text { Air-conditioning } \\
\text { (1HP) }\end{array}$ & 2 & 1.100 & 12 \\
\hline $\begin{array}{l}\text { Air-conditioning } \\
(1.5 \mathrm{HP})\end{array}$ & 2 & 1.400 & 8 \\
\hline
\end{tabular}

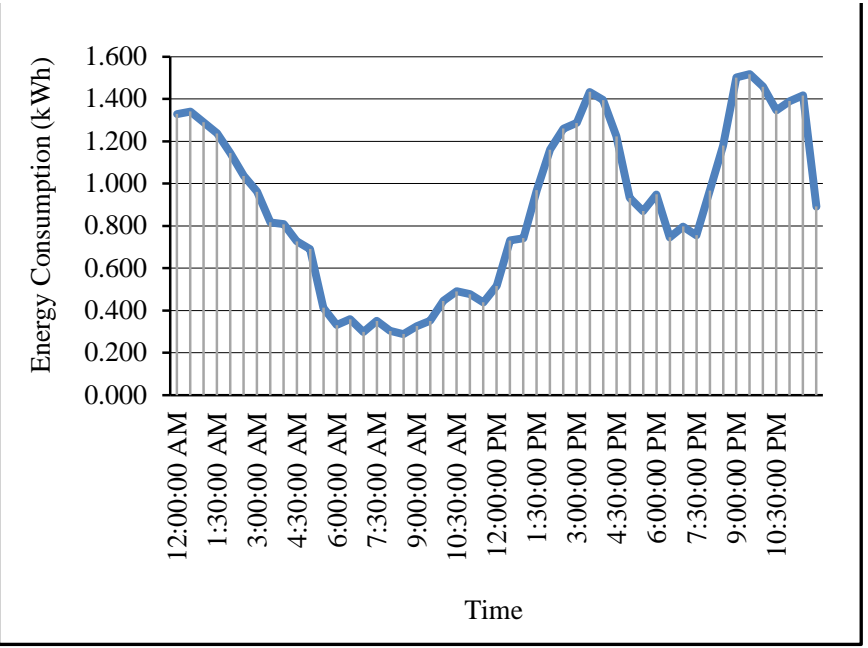

Fig. 2. Case 1 baseline energy consumption profile during $\mathrm{MCO}$ (average of the two weeks profile without awareness and SHEM

The general formulation that has been applied in finding the output of the study is presented below. The energy consumption $\mathrm{E}(\mathrm{kWh})$ and $\mathrm{Ec}(\mathrm{kWh} / \mathrm{MYR})$ are written as

$$
\begin{aligned}
& E=P T \\
& E c=P T^{*} S
\end{aligned}
$$

Where $\mathrm{P}$ is the power drawn with time $(\mathrm{T})$, and " $\mathrm{S}$ " represents the price per unit energy consumption based on the Ringgit Malaysia (MYR). The average based tariff has been adopted when dealing with part of the analysis of the results- the limitation set to follow flat tariff calculation instead of block tariff by energy provider in Peninsular Malaysia.

\section{RESULT}

The test results have been collected throughout the practice of the SHEM in the home, where the activities were set up to support the proposed method. Fig. 3 presents the comparison of the cases that represent the weekly average load profiles. It was observed that, when it was compared to Case 1, the topology of the energy consumption for Case 2 and Cases 3 were gradually reduced. In Case 2, there was the participation of the awareness program has contributed to reducing the peak energy consumption by approximately $13.3 \%$ (from 9:00 to 10:00 PM) Meanwhile, the waste of energy in the evening session was almost avoided when the consumption of the air-conditioning system was changed to the free flow of natural wind from outside. This action has been taken when doors and windows have been opened throughout the day. In Cases 3, when SHEM practice has participated in the house with the proper arrangement, the peak energy consumption was reduced for about 30.7 to $40 \%$ compared to the Case 2 and Case 1, respectively. It was observed that the daily load profiles for those Cases 3 that were applied by the SHEM method were sustained. Thus, this condition proves that the performance of the SHEM practice for the residential was valid while contributed to avoiding energy waste that was critically contributed by the household during MCO. 


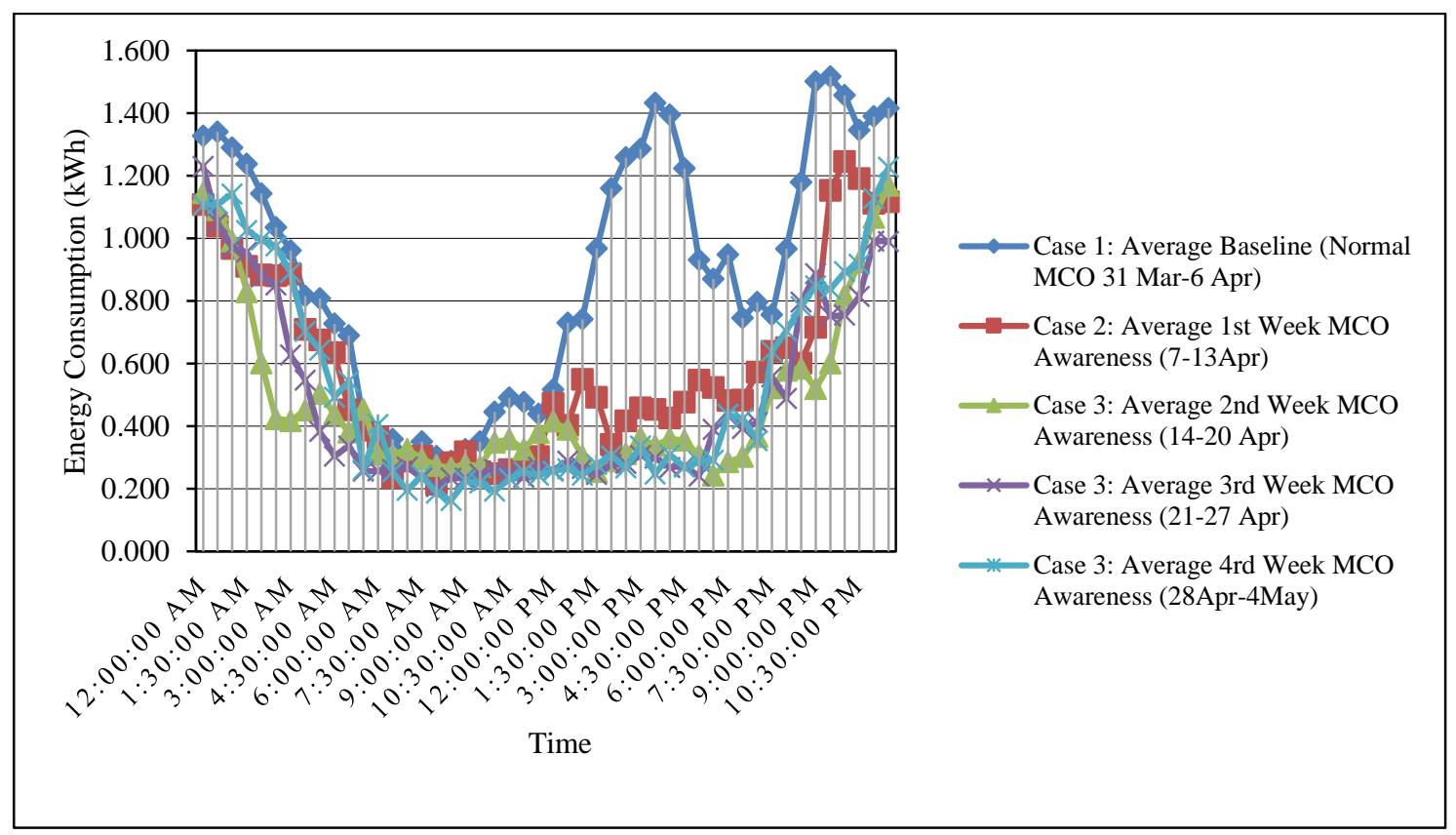

Fig. 3. Energy consumption profile during MCO for the total of 6 weeks

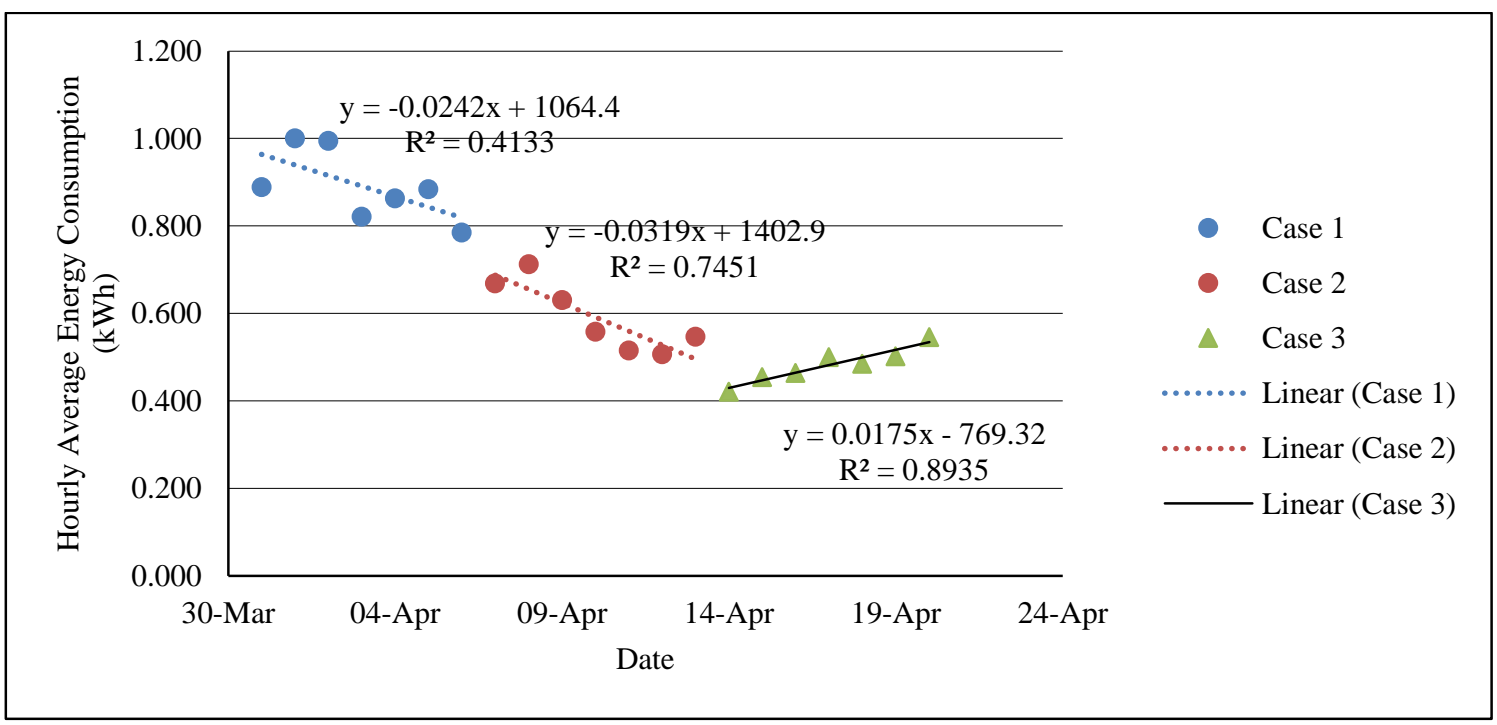

Fig. 4. Comparison of the average energy consumption topology between Case 1, Case 2 and Case 3

Inline to tabulated load profiles for those cases, Fig. 4 demonstrates the regression analysis of the average weekly load topology within 24 hours. The $\mathrm{R}^{2}$ for Case 3 has proven the significant correlation between every single hour of energy consumption that those energy wasted was avoided accordingly. Meanwhile, Case 2 shows the unstable condition of the awareness without proper planning where the consumption of the energy could be up and done irregularly. In this comparison, the SHEM technique can compute the excellent output of energy efficiency stability while promoting continuity factors for future improvement to avoid energy waste.
As the measurement of the SHEM method performance, Table 2 demonstrates the summary of the energy reduction, cost reduction, and the $\mathrm{CO} 2$ emission that could be achieved. The yearly performance has been forecasted base in the real case to show the significant achievement when SHEM with 5Cores procedure is applied, especially during the MCO of pandemic condition. Yearly energy consumption reduction is predicted to achieve approximately 46\%. Meanwhile, the spending electricity cost will be get mitigated for about $18 \%$ congruently. 
International Journal of Engineering Research and Technology. ISSN 0974-3154, Volume 13, Number 11 (2020), pp. $3189-3193$

(C) International Research Publication House. https://dx.doi.org/10.37624/IJERT/13.11.2020.3189-3193

Table 2. Comparison of the energy consumption reduction, cost benefit and CO2 emission of the SHEM program

\begin{tabular}{|l|l|l|l|}
\hline Results Consideration & Case 1 & Case 2 & Case 3 \\
\hline Total Weekly Energy Consumption $(\mathrm{kWh})$ & 299.45 & 198.72 & 161.06 \\
\hline Total Average Daily Energy Consumption $(\mathrm{kWh})$ & 42.78 & 28.389 & 23.01 \\
\hline Average hourly consumption (kWh) & 0.89 & 0.59 & 0.48 \\
\hline Yearly Energy Consumption Reduction (\%) & & 33.64 & 46.22 \\
\hline Yearly Cost Saving (MYR) & & $2,069.45$ & $2,843.21$ \\
\cline { 1 - 1 } Yearly Cost Reduction (\%) & & 13.25 & 18.21 \\
\cline { 1 - 1 } Yearly CO2 Emission reduction (KgCO2) & & $1,223.81$ & $1,681.39$ \\
\hline
\end{tabular}

\section{CONCLUSION}

The SHEM technique follows the good practice of energy efficiency, which is a combination of human effort to control energy waste. Simultaneously, SHEM considers the comfortable factor during the MCO of the pandemic, such as COVID-19 spreading in the country. Through the propose of SHEM, a non-technical person could adopt the simple 5Cores practice while the usage of the smart metering would be fully utilized. Future research could be integrated into the demand response program while the individual load profile to the energy needs analysis that reflects each other could be promoted. The TOU tariff offered by energy providers should be the advantage to the residential consumer where load management activities could contribute to the energy waste avoided and financial sustainability concurrently.

\section{ACKNOWLEDGMENTS}

The authors would like to thanks the Universiti Teknikal Malaysia Melaka (UTeM) for all the support given. Special thanks to the family in the house for the commitment to support the SHEM program during MCO. Appreciation also goes to the Sustainable Energy Department under Malaysia Green Technology and Climate Change Centre for the guide and essential information.

\section{REFERENCES}

[1] J. Palm and K. Reindl, "Understanding energy efficiency in Swedish residential building renovation: A practice theory approach," Energy Res. Soc. Sci., vol. 11, pp. 247-255, 2016.

[2] I. Dzene, I. Polikarpova, L. Zogla, and M. Rosa, "Application of ISO 50001 for Implementation of Sustainable Energy Action Plans," Energy Procedia, vol. 72, pp. 111-118, 2015.

[3] K. Seidel, "Improvement opportunities for the energy management systems standard," in ECEEE 2012 Summer Study On Energy Efficiency In Industry, Thailand, 2012, pp. 633-640.

[4] Malaysia Energy Commission, "Energy Management Gold Standard for Successful Energy Management Program," 2015.
[5] M. A. R. Muzmar, M. P. Abdullah, M. Y. Hassan, and F. Hussin, "Time of Use Pricing for Residential Customers Case of Malaysia," in IEEE Proceeding, 2015, pp. 589-593.

[6] N. A. M. Azman et al., "Impact of different time of use electricity pricing structure on residential consumer," Indones. J. Electr. Eng. Comput. Sci., vol. 10, no. 3, pp. 1053-1060, 2018.

[7] E. Shirazi and S. Jadid, "Cost Reduction and Peak Shaving Through Domestic Load Shifting and DERs," Energy, vol. 124, pp. 146-159, 2017.

[8] A. Saboor et al., "Home energy management in smart grid using evolutionary algorithms," in Proceedings International Conference on Advanced Information Networking and Applications, AINA, 2018, pp. 10701080 .

[9] S. Safarzadeh, M. Rasti-Barzoki, and S. R. Hejazi, “A review of optimal energy policy instruments on industrial energy efficiency programs, rebound effects, and government policies," Energy Policy, vol. 139, 2020.

[10] A. Kumar, S. Ranjan, M. B. K. Singh, P. Kumari, and L. Ramesh, "Electrical Energy Audit in Residential House," Procedia Technol., vol. 21, pp. 625-630, 2015

[11] Q. J. Kwong, J. E. Lim, and M. S. Hasim, "Miscellaneous electric loads in Malaysian buildings Energy management opportunities and regulatory requirements," Energy Strateg. Rev., vol. 21, pp. 3549, 2018. 